\title{
Evaluation of apical debris extrusion during root canal preparation using Hand K file, Revo S, Protaper Next and Wave One file system: An in vitro study.
}

\begin{abstract}
:
Introduction: The key step during the root canal treatment is the biomechanical preparation of the infected root canals. This preparation may result in pushing the apical debris through the apical foramen into the periapical space leading to initiation of immunological response by the host leading to postoperative pain and discomfort. Therefore the aim of the study was to compare the apical debris extrusion during root canal preparation using Hand k file, Revo S, Protaper Nextand Wave One file system.

Materials and Method: Sixty extracted human mandibular premolars with single canal were selected and randomly divided into four groups ( $n=15$ ) for instrumentation with four different files. Group 1: Hand k file, Group 2: RevoS file, Group 3: ProTaperNext, and Group 4: WaveOnesingle reciprocating file. Debris extruding during instrumentation were collected into pre-weighed Eppendorf tubes. These tubes were then stored in an incubator at $70^{\circ} \mathrm{C}$ for 5 days and were then weighed to obtain the final weight, with the extruded debris. Weight of extruded debris was calculated by subtracting the initial weight from the final weight. Statistical analysis was performed using one-way analysis of variance and post hoc Tukey's test.

Result: For intergroup comparison, significant differences were found for the debris extruded. Instrumentation with hand $\mathrm{K}$ files resulted in significantly more debris extrusion apically as compared to other three NiTi groups. Maximum debris extrusion was seen by Hand K file, followed by group 2(Revo S), then group 4(Wave One) and least by group 3(Protaper Next). However, there was no significant difference in debris extrusion amongst groups prepared with either NiTi rotary or reciprocating file systems.

Conclusion: The Pro Taper Next resulted in least debris extrusion when compared to Hand k file, reciprocating Wave One and rotary Revo S. However there was not a significant difference between all the NiTi rotary and reciprocating file system.
\end{abstract}

Keywords: Apical extrusion debris; Hand kfile, instrumentation; ProTaper Next, RevoS and Wave One.

\section{Introduction:}

Endodontic infections are commonly treated by Root canal treatment which includes the chemo-mechanical preparation i.e. use of files(Hand/Rotary) for the removal of the infected pulp and dentin and by the use of chemicals such as irrigant's and medicaments for elimination of remaining bacteria from the dentinal tubules within the root canal dentin. Even though various advancement have been introduced, but problems related with root canal shaping and cleaning procedures are usually the cause of flare-ups.[1]

During root canal treatment the extrusion of intracanal debris and irrigants is a common occurrence and no instrument or

\begin{tabular}{|l|l|}
\hline \multicolumn{3}{|c|}{ Access this article online } \\
\hline \multirow{2}{*}{$\begin{array}{l}\text { Website: } \\
\text { www.ujds.in }\end{array}$} & Quick Response Code \\
\hline $\begin{array}{l}\text { DOI: } \\
\text { https://doi.org/10.21276/10.21276/ujds.2020.6.2.22 }\end{array}$ & \\
\hline
\end{tabular}

\author{
${ }^{1}$ AGARWAL A, ${ }^{2}$ AKHTAR M S, ${ }^{3}$ MALICK M A, ${ }^{4}$ KHAN S, \\ ${ }^{5}$ YADAV S, ${ }^{6}$ AGARWAL S \\ ${ }^{1}$ Conservative Dentistry and Endodontics, Shahjahanpur \\ ${ }^{2}$ Conservative Dentistry and Endodontics, Moradabad \\ ${ }^{3}$ Conservative Dentistry and Endodontics, Bijnor \\ ${ }^{4}$ Periodontic and Oral Implantology, Moradabad \\ ${ }^{5}$ Conservative Dentistry and Endodontics, Ghaziabad. \\ ${ }^{6}$ Conservative Dentistry and Endodontics, \\ Kothiwal Dental College and Research Centre, \\ Moradabad
}

Address for Corresponding : Dr. Ankit Agarwal MDS, Conservative Dentistry and Endodontics S/o Mr. Ashok Kumar Agarwal Opposite Carew Ganj P.O. Rang Mehla, Shahjahanpur (UP) 242001 E-mail: ankitagarwal2424@gmail.com

Received : 14 July 2020, Published : 31 August 2020 
technique has been able to eliminate this problem completely. Any irritation directed towards periapical tissue may be the cause of flare-ups, therefore shaping or irrigation techniques should minimize the risk of extrusion periapically, even though it may not be completely prevented[1].

Irrigation is one of the most important steps in the successful root canal treatment and other inherent risks are likely to ensue without irrigation. Therefore, selecting a method that would decrease the amount of extrusion rather than completely eliminating the use of irrigants would be more logical.[2]

Biologically, all the source of irritants must be removed from the root canal space (RCS), and at the same time Biomechanical preparation should create an adequate space and shape for flushing and debridement. Complete debridement of the RCS using recently developed rotary/reciprocating files and newer irrigation systems can prove as an aid in predicting the successful outcome of the endodontic treatment.[3]

However, the irrigating solutions and the debris containing necrotic tissue, microorganisms, pulpal fragments, and dentin particles may be extruded from the RCS into the periapical region, may result in post-operative inflammation and ultimately leading to treatment failure4. The debris extrusion using different protocols of instrumentation and irrigation has been reported[5-12]. The amount of debris extruded is variable due to difference in the preparation techniques because of the various file systems and irrigation techniques.[5]

All the instrumentation techniques used for biomechanical preparation of the root canal space leads to apical extrusion of debris, even though the preparations are maintained short of the apical terminus3. Most nickel titanium (NiTi) File systems works on Crown-Down Technique with Push-Pull rotational movement of the Files. By the use of various advanced instrument design and implementation of different operational principles we can expect the favorable influence on the amount of debris extrusion.[3]

Reddy and Hicks compared the apical debris extrusion between hand instrumentation and engine-driven techniques and they concluded that the step-back technique produced significantly more debris than the engine-driven and the balanced-force technique.[11]

The Wave One (WO; Dentsply Maillefer, Ballaigues, Switzerland) is a single reciprocating file system that simulates a reversed balanced force and a linear motion.[3] ProTaper NEXT (PTN; Dentsply Tulsa Dental, Tulsa, OK) which is the most recent generation of shaping files presents uniqueness both with the center of mass and the center of rotation offset design. A mechanical wave of motion is produced by these files which travel along the active length of the file[4]. The advantages of this file design are minimizing the engagement between the file and dentin, and it may also enhance removal of debris out of a canal and improves flexibility of the files.[6]

The Revo-S NiTi rotary system(Micro-Mega, Besancon, France) include three shaping instruments: the shaping and cleaning instrument $\mathrm{SC} 1$, is a tip size 25 file with 0.06taper and it has an asymmetrical cross section, which is utilized to widen the coronal two thirds of the canal. The $\mathrm{SC} 2$ is a tip size $25,0.04$ tapered files used up to the full working length. The SC2 instrument has asymmetrical cross section and small tapering allowing better penetration. The three identical edges in the file design are present that balances the forces and guide the instrument up to the apical region of the canal. The universal shaper (SU) is a tip size 25, 0.06 tapered instruments which has an asymmetrical cross section. The system has additional 0.06tapered instruments for apical shaping and finishing (AS) at tip sizes30, 35 and 40, with a cutting length of $5 \mathrm{~mm}$.[13-14]

\section{Materials and Method:}

Sixty extracted human mandibular premolars with straight root and single canal were collected for the study. Confirmation of the single canal was done by radiographs. An access cavity kit (Endo Z Access Kit, Dentsply Tulsa) was used to make the coronal access cavity. $15 \mathrm{~K}$-file was use to achieve canal patency. The working length (WL) of each canal was determined as $1 \mathrm{~mm}$ short of the length of a size 15 $\mathrm{K}$-file that was visible at the apical foramen. The teeth were then randomly divided into four experimental groups for different instrumentation techniques. The present study used the experimental model (fig-1) described by Myers and Montgomery for assessing the debris extruded periapically.

An analytical balance (Shimadzu AW220, kyoto japan) with an accuracy of 10-4 $\mathrm{g}$ was used to measure the initial weights of the tubes. Three consecutive weights were obtained for each tube, and the mean was calculated. Each tooth was inserted up to the cemento-enamel junction, and a $27-G$ needle was placed alongside the stopper to balance the air pressure inside and outside the tubes and also for use as a drainage cannula. Then, each stopper with the tooth and the needle was attached to its Eppendorf tube, and the tubes were fitted into the glass vials. The same operator trained to use all the file systems efficiently carried out the instrumentation. The vial was covered with aluminum foil to blind the operator from seeing the apex during instrumentation. 


\section{Instrumentation:}

The glide path for all the 60 samples was created till \# $15 \mathrm{~K}$ file for all the groups and a new instrument/file (Hand K-file, Revo S file, Pro Taper Next file and Wave One file) was used for every sample of the respective groups.

\section{Group 1}

15 teeth were instrumented by hand $\mathrm{k}$ file in a step back manner. Apical preparation was done up to size 25 and the step back technique was used with a reduction of $1 \mathrm{~mm}$ in working length for an increment in each file size untill size 40 .

\section{Group 2}

15 teeth were instrumented by Revo $\mathrm{S}$ file system. Root canals were prepared with three shaping instruments at $300 \mathrm{rpm}$ and $1 \mathrm{Ncm}$ torque with torque controlled endodontic motor. The coronal two-third of the root canal were shaped and cleaned with $\mathrm{SC} 1$ file. On meeting obstruction the file was removed, the canal was irrigated, recapitulated, and the file was reintroduced into the canal. The instrumentation was done till the SC2 file reached the apex. The SC2 and the universal shaper (SU) were used at the WL.

\section{Group 3}

15 teeth were instrumented by Pro Taper Next file system. Root canals were prepared using PTN system with a gentle inand-out motion at $300 \mathrm{rpm}$ and $2 \mathrm{Ncm}$ torque with a torque controlled endodontic motor. The root canal orifice was enlarged using Sx file from the universal ProTaper (Dentsply Tulsa Dental, Tulsa, OK). This was followed by the use of X1 and $\mathrm{X} 2$ files. The instrumentation was continued till the X1 and $\mathrm{X} 2$ file both reached the working length.

\section{Group 4}

15 teeth were instrumented by single reciprocating file WO (primary) instrument, used in a pecking motion. The root canal orifice was enlarged using Sx file from the universal ProTaper (Dentsply Tulsa Dental, Tulsa, OK). A preprogrammed reciprocating endomotor (X-Smart Plus, Dentsply Maillefer) possessing the program for WO (small, primary, and large) files instrumentation was used. The flutes of the instrument were cleaned after three pecks. The instrumentation was done till the WO (primary) file reached the apex.

\section{Irrigation for the hand, rotary/reciprocating files:}

After each instrument (hand/rotary) or after three pecks (reciprocating) $2 \mathrm{~mL}$ of distilled water was used as irrigant. The irrigation needle (Dentsply Rinn Max I Probe) was placed as deep as possible into the canal but not deeper as the predetermined WL minus $1 \mathrm{~mm}$.

\section{Debris collection:}

Following instrumentation, the teeth were removed from the tube and the debris adhering to the root surface was collected by washing off the apical area of the tooth with $1 \mathrm{ml}$ of distilled water into the centrifuge tube. The centrifuge tube was stored in an incubator at $70^{\circ} \mathrm{C}$ for 5 days, to allow the moisture to evaporate, before weighing the dry debris, using an electronic balance.

\section{Statistical analysis:}

Data of the weights were statistically analyzed (Table-1) using the Shaperio-Wilk W test (p-value was more than 0.05 ). This was followed by application of one-way analysis of variance (ANOVA) and post hoc test to determine the significant group (statistical package of social sciences (SPSS) 16, SPSS Inc, Chicago, IL). Level of statistical significance was set at p-value less than 0.05 .

\section{Results:}

On applying Tukey post hoc test for intergroup comparison, significant differences were found for the debris extruded (Table-2). Instrumentation with hand $\mathrm{K}$ files resulted in significantly more debris extrusion apically as compared to other three NiTi groups i.e. Group 1 showed significantly greater debris extrusion than Group $2(\mathrm{p}=0.01)$, Group $3(\mathrm{p}=0.00)$ and Group $4(\mathrm{p}=0.00)$. It was seen that maximum debris extruded was by Hand $\mathrm{K}$ file, followed by Group 2(Revo S), then Group 4(Wave One) and least by Group 3(Protaper Next). However, there was no significant difference in debris extrusion amongst groups prepared with either NiTi rotary or reciprocating file systems. The difference between the debris extruded by Group 2 and Group $3(\mathrm{p}=0.25)$, Group 2 and Group $4(\mathrm{p}=0.67)$, Group 3 and Group $4(\mathrm{p}=0.88)$ failed to reach the level of significance.

\section{Discussion:}

The results obtained for the current study shows that the debris from instrumentation of root canals was extruded periapically regardless of the file design (square shape hand $\mathrm{k}$ file, asymmetrical Revo S, rectangular ProTaper Next, convex triangular Wave One) and different kinematic motions (reciprocating and rotary) used. The hand file resulted in maximum debris extrusion, whereas the Pro Taper Next file resulted in least debris extrusion in the four groups tested. To the best of our knowledge, there are no data in the literature on the extrusion of apical debris with the Hand $\mathrm{k}$ file, Revo $\mathrm{S}$, Protaper Next and Wave One file system. 
The present study used method of Myers and Montgomery to simulate clinical conditions. Distilled water was used as an irrigation solution to avoid any possible crystallization of sodium hypochlorite. The amount of periapically extruded debris being extremely low, the contact of moist or greasy finger tips may alter the weight of the extruded debris. Another important issue is the absence of a physical back pressure provided by periapical tissues, an imminent shortcoming of in vitro studies. Also, the residual pulp tissue, condition of the pulp, and normal or pathological periapical tissues may act as barriers and inhibit the apical extrusion in vivo conditions. The results obtained from the current study may be explained by differences in the instrument design and movement kinematics between the hand $\mathrm{k}$ file, Revo $\mathrm{S}$ file, ProTaper Next and Wave One file systems.

The hand $\mathrm{k}$ file was associated with the maximum debris extrusion apically in the present study, which is in accordance with other studies. Al-Omari\&Dummer compared eight different hand instrumentation methods and suggested that techniques involving a filing (linear) motion caused significantly more blockages and extruded significantly more apical dentine debris.[15]

Vande Visse \& Brilliant were the first to quantify the amount of apically extruded debris during instrumentation.[16] Ruiz - Hubard et al showed that instrumentation with an in-and-out motion tends to produce more apically extruded debris than instrumentation with rotational motion.[17]

Kustarci et al in also compared K3, RaCe and Flex Master files with hand instrumentation and concluded that hand instrumentation caused more extrusion of debris and bacteria when compared with these rotary instruments.[18]

In the present study, Revo S file system showed more debris extrusion than Wave One file system. This could be due to number of files used in the file system. Wave One file is a single file system with reciprocating motion whereas Revo $\mathrm{S}$ file is a multiple file system with rotary motion.

The PTN is a novel rotary file system and till date very few studies have evaluated apical extrusion of debris resulting from its instrumentation. The PTN possess a unique design, an offset center of mass and rotation. This design provides more cross-sectional space for enhanced cutting, loading and successfully allowing the debris to travel out of a canal (coronally), compared to a file with a centered mass and axis of rotation. It may also decrease the chances for the file packing the debris laterally, aiding in reducing the chances of blockage of the root canal system. ${ }^{3}$ This can be the main advantage of the file and may lead to least debris extrusion; hence, it was used as one of the instrumentation techniques for the present study. The samples in the group instrumented by PTN resulted in least extrusion of the debris when compared to the other file system.

The WO file was associated with the more debris extrusion than Pro Taper Next file apically in the present study. The WO files are characterized by a modified triangular cross-section, which results in decreased cutting efficacy and smaller chip space resulting in auguring the formed debris after instrumentation, periapically. The WO files also exhibit a larger taper of 0.08 at the apical $3 \mathrm{~mm}$, which can be attributed for excessive debris formation apically, and extrusion periapically.

Burklein et al conducted an in vitro study with reciprocating single file and full sequence rotary instrumentation system and found that reciprocating file produced more debris than rotary files. ${ }^{19}$ Ozsu et al. conducted an in vitro study with Pro Taper universal, Pro Taper Next, Wave One and Self adjusting file system and found that Pro Taper universal (rotary) extruded more debris than Pro Taper Next (rotary) and Wave One (reciprocating) file system and self adjusting file system showed least amount of debris extrusion apically. Results also showed that Pro Taper Next extrude less amount of debris apically than Wave one file system ${ }^{20}$, which is accordance with the our study. Ustun et al conducted an in vitro study with Wave One, twisted file and Pro Taper Next file system and concluded that reciprocating file Wave One extruded less debris than rotary file system Pro Taper Next and twisted file. ${ }^{21}$ Abozor et al conducted an in vitro study with Revo S, Pro Taper and Hero shaper file system and found that the differences between these three groups were not statistically significant.[22]

Although the study allows a comparison of the file systems under identical conditions, but there were some limitations. The main disadvantage of the method is that vital periapical tissues cannot be mimicked. Furthermore, this study was limited to the teeth with mature root morphology. The observed results should not be generalized to teeth with immature root development and the open apex. Furthermore, measuring the amount of extruded debris in terms of its weight is not adequate enough to make a speculation concerning a mid-treatment flare-up. There may be other factors such as extruded irrigant, intracanal medication, virulence of bacteria and the host response that can trigger such a flare-up. 


\section{Conclusion:}

Within the limitations of this study, it can be concluded that all systems extruded debris beyond the apical foramen. All the file system Pro Taper Next, Wave One and Revo S file system were significantly better than hand $\mathrm{K}$ file system in terms of amount of debris extrusion. Amongst the three NiTi systems, Pro Taper Next group resulted in the least debris extrusion, while Revo S group showed maximum debris extrusion with no significant difference between any of the NiTi file groups regardless of reciprocating or rotary motion. Further studies should evaluate the behavior of newly introduced NiTi systems in complicated root canals.

Table 1: Mean standard deviations (SD), median, minimum (min) and maximum $(\max )$ weight

\begin{tabular}{|l|l|l|l|l|l|}
\hline GROUPS & $\begin{array}{l}\text { MEAN } \\
\text { (gms) }\end{array}$ & $\begin{array}{l}\text { STANDARD } \\
\text { DEVIATIAN } \\
\text { (SD) (gms) }\end{array}$ & $\begin{array}{l}\text { MEDIAN } \\
\text { (gms })\end{array}$ & $\begin{array}{l}\text { MAXIMUM } \\
\text { (MAX) } \\
\text { (gms) }\end{array}$ & $\begin{array}{l}\text { MINIMUM } \\
\text { (MIN) } \\
\text { (gms) }\end{array}$ \\
\hline $\begin{array}{l}\text { GROUP 1 } \\
\text { (Hand K file) }\end{array}$ & 0.01137 & 0.00947 & 0.00940 & 0.03450 & 0.00180 \\
\hline $\begin{array}{l}\text { GROUP 2 } \\
\text { (Revo-S) }\end{array}$ & 0.00509 & 0.00418 & 0.00400 & 0.01530 & 0.00010 \\
\hline $\begin{array}{l}\text { GR0UP 3 } \\
\text { (Protaper Next) }\end{array}$ & 0.00142 & 0.001388 & 0.00090 & 0.00550 & 0.00010 \\
\hline $\begin{array}{l}\text { GROUP 4 } \\
\text { (Wave One) }\end{array}$ & 0.00286 & 0.002800 & 0.00160 & 0.01000 & 0.00020 \\
\hline
\end{tabular}

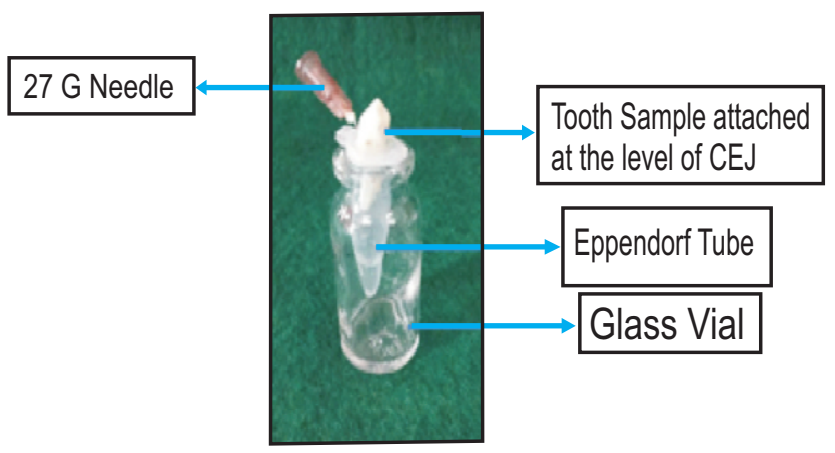

Fig. 1- Myers and Montgomery Model
Table 2- Post- hoc analvsis ( ${ }^{*}$ Sienificance of relationship at $<0.05$ )

\begin{tabular}{|l|l|l|l|l|}
\hline p value & $\begin{array}{l}\text { GROUP 1 } \\
(\mathrm{H})\end{array}$ & $\begin{array}{l}\text { GROUP 2 } \\
(\mathrm{R})\end{array}$ & $\begin{array}{l}\text { GROUP 3 } \\
(\mathrm{PN})\end{array}$ & $\begin{array}{l}\text { GROUP 4 } \\
(\mathrm{WO})\end{array}$ \\
\hline GROUP 1 (H) & - & $0.00 * 1$ & $0.00 *$ & $0.00 *$ \\
\hline GROUP 2 (R) & - & - & 0.25 & 0.67 \\
\hline GROUP 3 (PN) & - & - & - & 0.88 \\
\hline GROUP 4 & - & - & - & - \\
(WO) & & & & \\
\hline
\end{tabular}

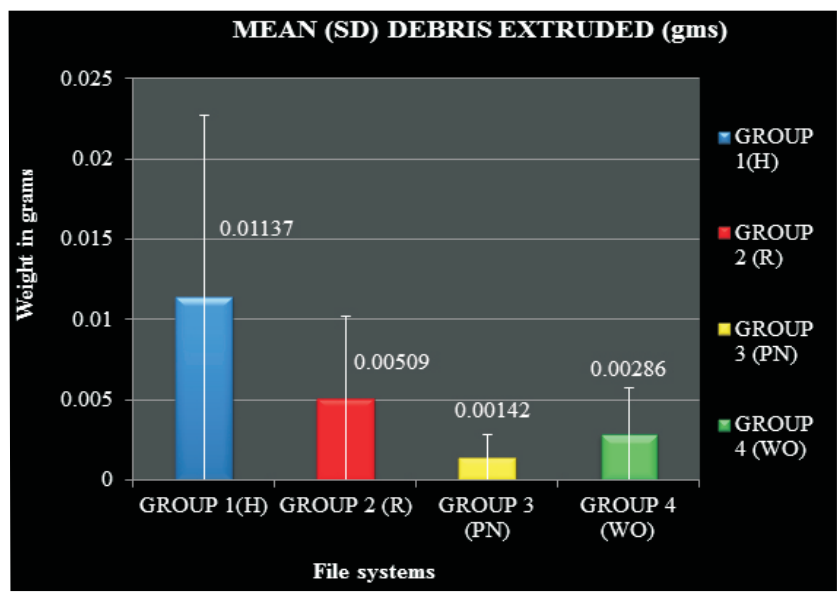

Fig. 2: Mean and standard deviation (SD), median minimum (min) and maximum (max) weight grams of debris extruded apically in each group.

\section{References:}

1. Tanalp J, Gungor T. Apical extrusion of debris: a literature review of an inherent occurrence during root canal treatment. IntEndod J. 2014 ;47(3):211-21.

2. Seltzer S, Naidorf IJ. Flare-ups in endodontics: etiological factors. J. Endod. $1985 ; 11: 472-8$.

3. Pawar AM, Pawar MG, Metzger Z, Kokate SR. The selfadjusting file instrumentation results in less debris extrusion apically when compared to WaveOne and ProTaper NEXT J Cons Dent. 2015; 18(2) : 80-93.

4. Ghivari SB, Kubasad GC, Deshpande P. Comparative evaluation of apical extrusion of bacteria using hand and rotary systems: An in vitro study. J Cons Dent 2012;15:32-5.

5. Koçak S, Koçak MM, Sağlam BC, Türker SA, Sağsen B, Er Ö. Apical extrusion of debris using self-adjusting file, reciprocating single-file, and 2 rotary instrumentation systems. J Endod 2013;39:1278-80. 
6. Ruddle CJ, Machtou P, West JD. The shaping movement: Fifth-generation technology. DentToday 2013;32:94, 96-9.

7. De Deus GA, Nogueira Leal Silva EJ, Moreira EJ, de Almeida Neves A, Belladonna FG, Tameirão M. Assessment of apically extruded debris produced by the self-adjusting file system. J Endod 2014;40: 526-9.

8. Surakanti JR, Venkata RP, Vemisetty HK, Dandolu RK, Jaya NM, Thota S. Comparative evaluation of apically extruded debris during root canal preparation using ProTaperTM, Hyflex TM and Wave one TM rotary systems. J Cons Dent 2014;17: 129-32

9. Myers GL, Montgomery S. A comparison of weights of debris extruded apically by conventional filing and Canal Master techniques. JEndod 1991;17: 275-9.

10. Capar ID, Arslan H, Akcay M, Erats H. An in vitro comparison of apically extruded debris and instrumentation times with ProTaper Universal, ProTaper Next, Twisted File Adaptive and HyFlex instruments. J Endod 2014; 40: 1638-41.

11. Bonaccorso A, Cantatore G, Condorelli GG, Schäfer E, Tripi TR. Shaping ability of four nickel- titanium rotary instruments in simulated S-shaped canals. J Endod 2009; 35: 883-6.

12. Mohorn HW, Dowson J, Blankenship JR. Odonticperiapical pressure following vital pulp extirpation. Oral Surg Oral Med Oral Pathol 1971; 31: 536-44.

13. Abozor BM, Awad N. Apically Extruded Debris and Irrigant Using the Revo-S System. J Interdiscipl Med Dent Sci. 2015; 3:2.

14. Yeter KY, Evcil MS, Ayranci LB, Ersoy I. Weight of apically extruded debris following use of two canal instrumentation techniques and two designs of irrigation needles. IntEndod J 2013; 46: 795-99.

15. Al-Omari MAO, Dummer PMH (1995) Canal blockage and debris extrusion with eight preparation techniques. $J$ Endod. 1995; 21: 154-8.

16. Van de Visse J, Brilliant JD (1975) Effect of irrigation on the production of extruded material at the root apex during instrumentation. JEndod. $1975 ; 1: 243-6$.

17. Ruiz-Hubard EE, Gutmann JL, Wagner MJ. A quantitative assessment of canal debris forced periapically during root canal instrumentation using two different techniques. JEndod. 1987 ; 13: 554-8.

18. Kustarci A, Akdemir N, Siso SH, Altunbas D. Apical Extrusion of Intracanal Debris Using Two Engine Driven and Step-Back Instrumentation Techniques: An In-Vitro Study. European Journal of Dentistry. 2008; 2: 233-9.

19. Bürklein S, Schäfer E. Apically extruded debris with reciprocating single-file and full-sequence rotary instrumentation systems. J Endod 2012; 38: 850-2.
20. Ozsu D, KaratasE, Arslan H, Topcu MC. Quantitative evaluation of apically extruded debris during root canal instrumentation with Pro Taper Universal, ProTaper Next, Wave One, and self-adjusting file systems. European Journal of Dentistry. 2014; 8(4) : 504-8.

21. Ustun Y, Canakci BC, Dincer AN, Er O, Duzgun S.Evaluation of apically extruded debris associated with several Ni-Ti systems. IntEndod J.2015 ; 48(7) : 701-4.

22. Abozor BM, Awad N. Apically Extruded Debris and Irrigant Using the Revo-S System. J Interdiscipl Med Dent Sci. 2015;3:2. 